\title{
Legg-Calvé-Perthes disease
}

INSERM

\section{Source}

INSERM. (1999). Orphanet: an online rare disease and orphan drug data base. Legg-

Calvé-Perthes disease. ORPHA:2380

Legg-Calve-Perthes disease (LCPD) is the term used to describe uni- or bilateral avascular necrosis (AVN) of the femoral head in children. 